\title{
Faktor-Faktor yang Mempengaruhi Adopsi Aplikasi Go-Pay Menggunakan UTAUT2
}

\author{
Deny \\ Program Studi Sistem Informasi, Universitas Bunda Mulia, Jakarta, Indonesia \\ deny@pembelajarhidup.com
}

Diterima 7 Maret 2019

Disetujui 24 Juni 2019

\begin{abstract}
E-money adoption can lead to faster ecommerce business development in the country. Unfortunately, e-money adoption percentage in Indonesia is still very far behind developed countries. Therefore, more studies about e-money adoption determinant factors in Indonesia are needed to improve adoption. Sample of this study was 422 Go-Pay users in Indonesia, taken by online form. The data was analized using SEM technique by Lisrel. Result shows that use intention of e-money is determined by hedonic motivation, social influence, habit and price value. Performance expectancy, effort expectancy, and facilitating conditions were found not significant factors of use intention of e-money. Interestingly, the real usage of e-money is not determined by facilitating conditions but still significantly influenced by habit and use intention of e-money. Result of this study are useful for e-money entrepreneurs who need to improve e-money application usage in Indonesia by focusing on providing features and incentives for user enjoyment and social influence.
\end{abstract}

Index Terms - e-money, go-pay, online payment, use intention, UTAUT

\section{PENDAhUluAN}

Perkembangan yang sangat pesat dari penggunaan e-money di Indonesia telah mengokohkan aplikasi e- money sebagai salah satu e-money yang harus diperhitungkan. Data dari Tecinasia [2] menunjukkan pertumbuhan yang signifikan dari sisi volume transaksi maupun nilai transaksi e-money (Gambar 1). Dari 41 juta transaksi pada 2011 meningkat menjadi 535 juta transaksi di tahun 2017. Sedangkan dari sisi nilai, tahun 2011 nilai transkasi e-money baru sebesar 981 milyar saja, dan meningkat pesat ke 5 trilyun di tahun 2017.

Adapun Go-Pay telah mengklaim bahwa 30\% dari keseluruhan transaksi e-money tersebut menggunakan aplikasi Go-Pay. Pesaing dari aplikasi tersebut adalah Ovo dan T-cash [2]. Ovo sendiri mengklaim telah dapat diterima di $70 \%$ pusat pembelanjaan di [16]

Penetrasi e-money untuk pembelajaan online merupakan salah satu kunci untuk memperluas pasar e-commerce di Indonesia. Seperti diketahui, salah satu kendala dalam mengembangkan e-commerce di Indonesia adalah finansial infrastruktur. Secara khusus, penetrasi kartu kredit di Indonesia baru mencapai $10 \%$ dari total 250 juta penduduk, sedangkan di Korea Selatan sudah mencapai $70 \%$ [12]. Karena itu keberhasilan penggunaan e-money dapat mendukung penyebaran e-commerce secara signifikan yang pada waktunya dapat mengembangkan perekonomian Indonesia juga secara signifikan.

Tabel 1. Volume dan Nilai Transaksi E-Money

\begin{tabular}{|l|r|r|r|r|r|}
\hline & \multicolumn{1}{|c|}{$\mathbf{2 0 1 1}$} & \multicolumn{1}{c|}{$\mathbf{2 0 1 2}$} & \multicolumn{1}{c|}{$\mathbf{2 0 1 3}$} & \multicolumn{1}{c|}{$\mathbf{2 0 1 4}$} & \multicolumn{1}{c|}{$\mathbf{2 0 1 5}$} \\
\hline Volume & $41,060,149$ & $100,623,916$ & $137,900,779$ & $203,369,990$ & $535,579,528$ \\
\hline $\begin{array}{l}\text { Nilai } \\
\text { juta rupiah) }\end{array}$ & 981,297 & $1,971,550$ & $2,907,432$ & $3,319,556$ & $5,283,018$ \\
\hline
\end{tabular}

Sumber: Techinasia (2019)

Atas dasar tersebut, maka dibutuhkan studi-studi mengenai faktor-faktor apa yang menjadi determinan untuk adopsi teknologi e-money tersebut.

Riset ini sangat penting untuk pengembangan bisnis e-money di Indonesia, di mana para pengusaha (dan calon pengusaha) akan mendapatkan pengetahuan tentang faktor-faktor apa yang harus diatasi agar bisnis mereka dapat berjalan dengan sukses.
Untuk menemukan faktor-faktor determinan tersebut salah satu model yang menjelaskan dengan komprehensif adalah UTAUT, yang sudah direvisi menjadi UTAUT 2. 


\section{KAJIAN PUSTAKA DAN HIPOTESIS}

\section{A. E-Money}

E-money atau uang elektronik menurut bank central Eropa didefinisikan sebagai penyimpanan elektronik suatu nilai moneter pada suatu perlengkapan teknis yang dapat digunakan untuk pembayaran entiti di luar pihak yang mengeluarkan emoney tersebut. Perlengkapan teknis tersebut berfungsi sebagai instrumen pra-bayar yang tidak mengharuskan melibatkan akun bank dalam melakukan transaksi [1].

Sedangkan dalam situs resmi Kementrian Keuangan Republik Indonesia, berdasarkan Peraturan Bank Indonesia Nomor 18/ 17/PBI/2016, tertulis bahwa $e$-money diterbitkan atas dasar nilai uang yang disetor terlebih dahulu oleh pemegang kepada penerbit dan nilai uang tersebut disimpan secara elektronik dalam suatu media seperti server atau chip. E-money bukan hanya sebagai pengganti uang tunai fisik dalam bentuk koin dan uang kertas dengan uang elektronik yang setara, namun juga sebagai sebuah sistem yang memungkinkan seseorang untuk membayar barang atau jasa dengan mengirimkan nomor dari satu komputer ke komputer lain [6]

Berdasarkan teknologi yang digunakan, $e$ money ada dua macam [1]: berbasis perangkat keras dan berbasis perangkat lunak. Berbasis perangkat keras misalnya kartu chip, sedangkan berbasis perangkat lunak misalnya Go-Pay, Ovo, T-Cash.

Go-Pay, adalah fitur uang elektronik yang terdapat dalam aplikasi Go-jek yang sudah mendapatkan ijin dari Otoritas Jasa Keuangan, serta menuruti standar-standar yang ditetapkan oleh Bank Indonesia. Beberapa waktu terakhir ini, Go-Jek sebagai perusahaan yang mengusung Go-Pay melakukan promosi dengan gencar agar masyarakat menggunakan Go-Pay, bahkan untuk transaksitransaksi dengan para UMKM..

\section{B. UTAUT}

UTAUT singkatan dari Unified Theory of Acceptance and Use of Technology dirumuskan pertama kali oleh Venkatesh, Morris, Davis, and Davis pada tahun 2003 [15]. UTAUT versi awal ini mengidentifikasi 4 faktor yang mempengaruhi penggunaan teknologi yaitu harapan kinerja, harapan usaha, pengaruh sosial dan kondisi yang mendukung. Keempat faktor tersebut dimoderasi oleh 4 moderator yaitu usia, gender, pengalaman dan kesukarelaan. Kemudian UTAUT direvisi menjadi UTAUT 2 dengan menambahkan motivasi hedonik, persepsi harga dan kebiasaan sebagai faktor yang mempengaruhi penggunaan teknologi.

UTAUT 2 memberikan penjelasan yang sangat komprehensif tentang bagaimana adopsi teknologi dilakukan, melebihi model adopsi teknologi lainnya seperti TAM (Technologi Acceptance Model). Dalam model UTAUT2, intensi penggunaan (behavioral intention) akan dipengaruhi oleh harapan kinerja (performance expectation), harapan usaha (effort expectation), pengaruh sosial (social influence), dan kondisi yang mendukung (facilitating condition), motivasi hedonik (hedonic motivation), persepsi harga (price value), dan kebiasaan (habit) [15].

Sedangkan penggunaan teknologi yang sebenarnya dipengaruhi oleh 3 faktor yaitu intensi penggunaan, kondisi yang mendukung dan kebiasaan [13].

Adapun Deningtyas [5] telah melakukan studi tentang faktor-faktor yang mempengaruhi penggunaan Go-Pay di Bandung menggunakan juga model UTAUT2, menemukan bahwa bahwa kebiasaan adalah faktor paling berpengaruh terhadap keinginan untuk menggunakan Go-Pay, diikuti persepsi harga, harapan kinerja, pengaruh sosial dan motivasi hedonik. Sedangkan dua faktor lainnya yaitu kondisi mendukung dan harapan usaha tidak berpengaruh signifikan.

\section{Faktor-Faktor Penentu Adopsi}

Harapan kinerja didefinisikan sebagai suatu tingkat di mana seseorang percaya bahwa penggunaan sistem akan membantu dia untuk meningkatkan kinerja dirinya dalam pekerjaan [8]. Harapan akan kinerja diperkirakan sebagai faktor utama yang paling signifikan dalam adopsi teknologi, di mana harapan kinerja berpengaruh positif terhadap adopsi teknologi.

Harapan usaha adalah tingkat kemudahan dalam menggunakan suatu sistem [8]. Ini berarti ukuran tingkat usaha yang harus dikeluarkan dan juga tingkat pembelajaran yang harus dilakukan dalam persepsi pengguna untuk dapat menggunakan teknologi tersebut dengan nyaman. Harapan usaha dari berbagai penelitian [8][14] terbukti mempengaruhi secara positif keinginan untuk menggunakan.

Pengaruh sosial merupakan suatu tingkat persepsi pengguna tentang apakah orang lain yang penting baginya (important others) berpikir bahwa pengguna tersebut harus menggunakan sistem tersebut [8]. Faktor ini melibatkan pengaruh orang-orang yang penting bagi pengguna untuk menggunakan sistem atau teknologi. Pengaruh sosial memberikan pengaruh signifikan dan positif bagi intensi penggunaan teknologi.

Kondisi yang mendukung adalah persepsi pengguna tentang apakah ada sumber daya dan pendukung (support) yang tersedia untuk menggunakan sistem tersebut [14]. Ini berarti termasuk bantuan baik secara digital, artikel, buku maupun bantuan manusia lain yang tersedia ketika pengguna mengalami kesulitan dalam menggunakan sistem tersebut. Kondisi yang mendukung ini pun merupakan faktor yang berpengaruh secara positif baik bagi intensi penggunaan suatu sistem, juga bagi penggunaan sebenarnya.

Motivasi Hedonik didefinisikan sebagai kesenangan yang didapat dari penggunaan teknologi. 
Dalam penelitian mengenai faktor-faktor penentu penggunaan teknologi untuk toko daring [3][4] ditemukan bahwa faktor kesenangan adalah faktor utama yang berpengaruh positif dalam adopsi teknologi untuk melakukan jualan daring. Hal ini juga sesuai dengan hasil penelitian dari Venkatest, Thong dan Xu [14], dan Rauniar, Greg, Jei, \& Ben [10].

Harga ditemukan sebagai hal yang berpengaruh secara signifikan terhadap penggunaan teknologi untuk suatu sistem yang berbayar [14]. Persepsi harga (price value) didefinisikan sebagai suatu kompromi secara kognitif antara persepsi keuntungan dengan biaya finansial yang harus dikeluarkan untuk menggunakannya. Namun dalam konteks aplikasi emoney Go-Pay, pengguna tidak perlu mengeluarkan uang untuk menginstalnya, malahan dalam masa promosi Go-Pay banyak memberikan diskon-diskon untuk pembelian menggunakan Go-Pay. Karena itu dalam penelitian ini persepsi harga merupakan persepsi pengguna akan keuntungan secara finansial dengan menggunakan Go-Pay.

Habit atau kebiasaan didefinisikan sebagai suatu tingkat manusia melakukan suatu perilaku secara otomatis sebagai hasil dari pembelajaran [14]. Kebiasaan dapat dilihat sebagai hal yang sudah terjadi di masa lalu, tetapi dapat juga dilihat sebagai persepsi pengguna. Kebiasaan dalam penelitian Venkatest, Thong dan $\mathrm{Xu}$ [14], dan Tak \& Panwar [9] berpengaruh secara positif signifikan terhadap keinginan untuk menggunakan. Kebiasaan juga berpengaruh positif dan signifikan terhadap penggunaan teknologi yang sebenarnya.

\section{Hipotesis}

Dari penjabaran tinjauan pustaka di atas, maka diusulkanlah hipotesis-hipotesis sebagai berikut:

H1. Harapan kinerja (HK) secara positif mempengaruhi intensi penggunaan aplikasi Go-Pay (IP).

H2. Harapan usaha (HU) secara positif mempengaruhi intensi penggunaan aplikasi Go-Pay (IP).

H3. Pengaruh sosial (PS) secara positif mempengaruhi intensi penggunaan aplikasi Go-Pay (IP).
H4. Motivasi Hedonik (MH) secara positif mempengaruhi intensi penggunaan aplikasi Go-Pay (IP).

H5. Persepsi harga (PH) secara positif mempengaruhi intensi penggunaan aplikasi Go-Pay (IP).

H6. Kondisi mendukung (KM) secara positif mempengaruhi intensi penggunaan aplikasi Go-Pay (IP).

H7. Kebiasaan (K) secara positif mempengaruhi intensi penggunaan aplikasi Go-Pay (IP)

H8. Kondisi mendukung (KM) secara positif mempengaruhi penggunaan aplikasi Go-Pay (P)

H9. Kebiasaan (K) secara positif mempengaruhi penggunaan aplikasi Go-Pay (P)

H10. Intensi penggunaan (IP) secara positif mempengaruhi penggunaan teknologi Go-Pay (P)

Dari kesepuluh hipotesis di atas, maka dapat digambarkan hubungan antar variabel dalam penelitian ini seperti pada Gambar 1.

\section{Metode PENELITIAN}

\section{A. Desain Penelitian dan Pengambilan Sampel}

Penelitian ini adalah riset kausalitas di mana dicari faktor penyebab variabel-variabel bebas (HK, HU, PS, $\mathrm{KM}, \mathrm{MH}, \mathrm{PH}$ dan $\mathrm{K}$ ) yang mempengaruhi variabel tidak bebas (P) melalui variabel intervening (IP) [13]. Riset ini merupakan riset pengujian hipotesis dengan menggunakan data kuantitatif.

Survei digunakan untuk mendapatkan data primer intensi penggunaan aplikasi e-money Go-Pay. Data diambil sekali saja (cross sectional) dari para responden, dan dikumpulkan dalam suatu jangka waktu tertentu. Data primer diambil menggunakan kuisioner dengan pertanyaan tertutup, yang disebarkan secara online menggunakan Google Drive Form.

Pengambilan sampel yang dilakukan adalah convenience sampling, dengan jumlah sampel setidaknya sebanyak 5 kali variabel teramati [6] 


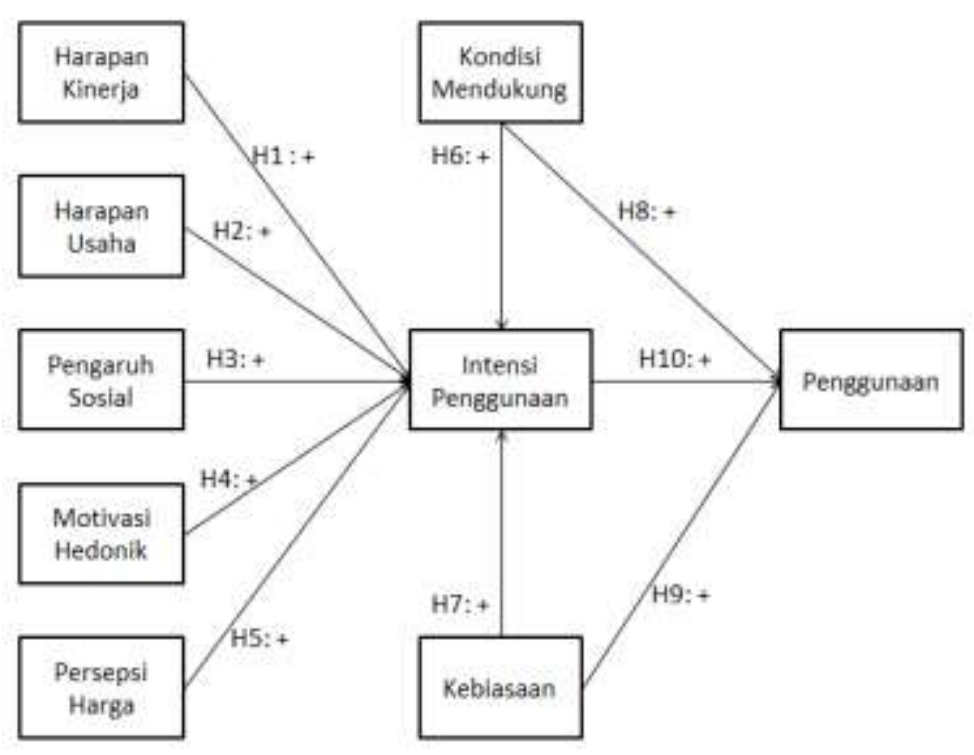

\section{Gambar 1. Operasionalisasi Variabel Penelitian}

\section{B. Pengembangan Instrumen}

Indikator-indikator yang digunakan dalam penelitian ini secara umum diambil dari indikatorindikator dalam penelitian-penelitian sebelumnya [8][9][14] yang sudah teruji dalam penelitian mereka. Namun indikator-indikator tersebut sedikit disesuaikan dengan konteks adopsi aplikasi Go-Pay

Selain menggunakan indikator-indikator tersebut, digunakan juga beberapa indikator yang diklaim oleh Go-Jek sebagai faktor penyebab penggunaan Go-Pay [2] yaitu: adanya promo atau potongan harga (variabel persepsi harga), tidak perlu menyiapkan uang pas (variabel harapan kinerja), mudah digunakan (variabel harapan usaha).

Indikator-indikator selengkapnya adalah sebagai berikut:

1. Variabel Harapan Kinerja:

- Go-Pay berguna bagi saya [8][9][14]

- Dengan Go-Pay, saya menyelesaikan pembayaran dengan lebih cepat [8][14]

- Go-Pay membantu saya lebih efisien [8] [9] [14]

- Dengan Go-Pay saya tidak perlu menyiapkan uang pas [2]

2. Variabel Harapan Usaha:

- Cara menggunakan Go-Pay mudah dipelajari [8] [9] [14]

- Aplikasi Go-Pay jelas dan mudah dimengerti [14]

- Go-Pay mudah digunakan [2] [9] [14]
3. Pengaruh Sosial:

- Orang yang penting bagi saya menyarankan agar saya menggunakan Go-Pay [8] [9] [14]

- Orang yang mempengaruhi tingkah laku saya menyarankan agar saya menggunakan Go-Pay [8] [9] [14]

- Orang yang pendapatnya saya hargai menyarankan agar saya menggunakan Go-Pay [14]

Saya menggunakan Go-Pay karena sudah banyak orang yang menggunakannya [9]

4. Kondisi Mendukung:

Saya memiliki gadget dan koneksi internet yang dibutuhkan untuk menggunakan Go-Pay [8] [9] [14]

- Saya mudah mendapatkan pengetahuan yang diperlukan (misalnya petunjuk penggunaan) untuk menggunakan Go-Pay [9]

- Go-Pay dapat dijalankan di gadget yang saya miliki [9] [14]

- Saya akan mendapatkan bantuan dari orang lain apabila saya mengalami kesulitan dalam menggunakan Go-Pay [8] [14]

5. Motivasi Hedonik:

- Menggunakan Go-Pay itu menyenangkan [14]

- Saya menikmati menggunakan Go-Pay [14]

- Menggunakan Go-Pay itu sangat menarik [9] 
6. Persepsi harga:

- Go-Pay memberikan diskon yang menguntungkan [2] [9]

- Dengan Go-Pay harga barang menjadi lebih murah [2] [9]

- Go-Pay membantu saya berhemat [2] [9]

7. Kebiasaan:

- Saya sudah biasa menggunakan Go-Pay [9] [14]

- Saya terbiasa menggunakan Go-Pay terlebih dahulu sebelum menggunakan uang kontan [9]

- Saya harus menggunakan Go-Pay [9] [14]

- Saya kecanduan menggunakan Go-Pay [9] [14]

8. Intensi Penggunaan:

- Saya ingin menggunakan Go-Pay di masa depan [8] [9] [14]

- Saya akan selalu mencoba menggunakan GoPay dalam keseharian saya [8] [9] [14]

- Saya berencana untuk terus menggunakan GoPay [9] [14]

9. Penggunaan:

- Seberapa sering Anda menggunakan Go-Pay? (tidak pernah, jarang, kadang-kadang, sering, selalu) [14]

Seluruh indikator kecuali indikator variabel Penggunaan akan diukur menggunakan skala Likert 1 (sangat tidak setuju) sampai dengan 5 (sangat setuju). Khusus indikator variabel Penggunaan, akan digunakan skala Likert 1 (tidak pernah) sampai dengan 5 (selalu).

\section{Teknik Analisis}

Analisis data dilakukan menggunakan SEM dengan bantuan perangkat lunak Lisrel 8.71, dengan menggunakan uji t. Sedangkan uji validitas dan reliabilitas menggunakan Confirmatory Factor Analysis.

2 Persaman model struktural pada penelitian ini adalah sebagai berikut:

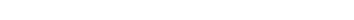$$
(\mathrm{IP}=\mathrm{HK}+\mathrm{HU}+\mathrm{PS}+\mathrm{KM}+\mathrm{MH}+\mathrm{PH}+\mathrm{K}+
$$
Error antar variabel)

$$
\begin{aligned}
& \eta_{2}=\gamma_{42} \xi_{4}+\gamma_{72} \xi_{7}+\beta_{12} \eta_{1}+\zeta_{2} \\
& (P=K M+K+I P+\text { Error antar variabel })
\end{aligned}
$$

Gambar 2 menjelaskan diagram jalur dalam penelitian ini, di mana

$$
\begin{aligned}
& \xi_{1}=\text { Harapan Kinerja (HK) } \\
& \text { ६2 = Harapan Usaha (HU) } \\
& \xi 3=\text { Pengaruh Sosial (PS) } \\
& \xi 4=\text { Kondisi Mendukung (KM) } \\
& \xi 5=\text { Motivasi Hedonik (MH) } \\
& \xi 6=\text { Persepsi Harga (PH) } \\
& \xi 7=\text { Kebiasaan }(\mathrm{K}) \\
& \text { ¡1 = Intensi penggunaan } \\
& \text { ฤ2 = Penggunaan }
\end{aligned}
$$

\section{HASIl PENELITIAN DAN PEMBAhasan}

Kuisioner yang disebarkan mendapatkan responden sejumlah 422 orang. Pengujian CFA yang dilakukan terhadap konstruk eksogen dan endogen model penelitian menunjukkan variabel teramati berikut memiliki loading faktor yang lebih rendah dari 0.7, sehingga dikeluarkan dari model:

- HK1 (Sekalipun jika tidak ada diskon yang ditawarkan, aplikasi Go-Pay tetap bermanfaat bagi saya)

- HK4 (Dengan Go-Pay saya tidak perlu menyiapkan uang pas)

PS4 (Saya menggunakan Go-Pay karena sudah banyak orang yang menggunakannya)

KM3 (Go-Pay dapat dijalankan di gadget yang saya miliki)

KM4 (Saya akan mendapatkan bantuan dari orang lain apabila saya mengalami kesulitan dalam menggunakan Go-Pay)

- K2 (Saya terbiasa mencoba menggunakan GoPay terlebih dahulu sebelum menggunakan uang kontan)

- K3 (Saya merasa harus menggunakan kursus online dibandingkan kursus tatap muka tradisional)

Selain indikator-indikator di atas, variabel lainnya telah memenuhi persyaratan uji validitas dan reliạbilitâs yaitu loading faktor, CR dan VE yang baik.

Pengujian GOF (goodness of fit) juga menunjukkan chi-square, nilai P, AGFI, NFI, CFI dan CN yang fit (mewakili kriteria kesesuaian absolut, inkremental dan parsimoni, [7]). 


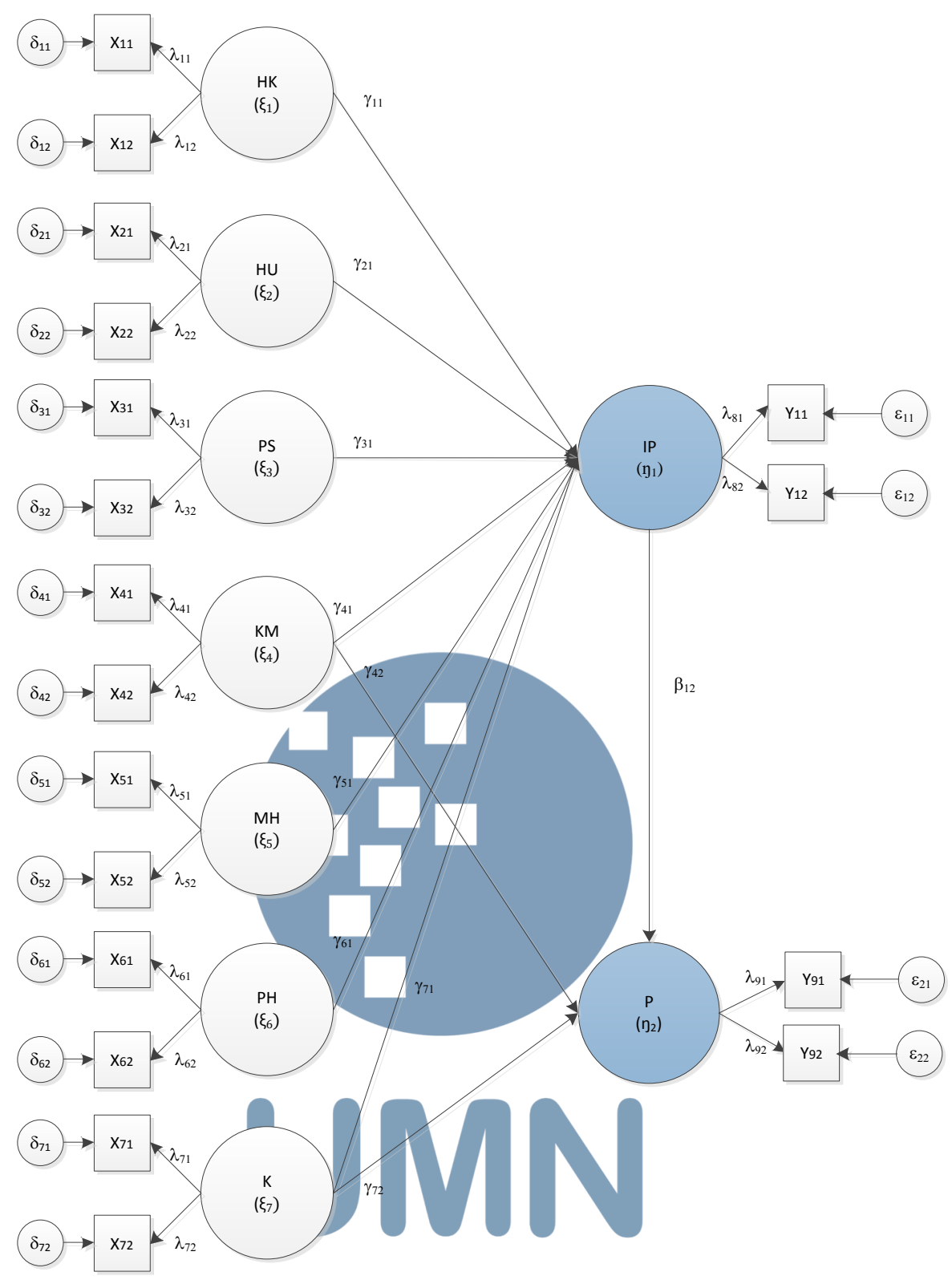

Gambar 2. Diagram Jalur

Tabel 2 menunjukkan hasil uji signifikansi model, bahwa variabel Harapan Kinerja, Harapan Usaha, Kondisi Mendukung tidak berpengaruh secara signifikan terhadap Intensi Penggunaan. Demikian juga tidak ditemukan adanya pengaruh signifikan dari variabel Kondisi Mendukung terhadap Penggunaan Go-Pay.

Analisis model struktural memberikan persamaan struktural sebagai berikut:

$\mathrm{IP}=0.092 \mathrm{HK}+0.0038 \mathrm{HU}+0.29 \mathrm{PS}-0.062 \mathrm{KM}+$ $0.42 \mathrm{MH}+0.12 \mathrm{PH}+0.16 \mathrm{~K}$

Errorvar $=0.28, \mathrm{R}^{2}=0.72$ $\mathrm{P}=0.40 \mathrm{IP}-0.10 \mathrm{KM}+0.45 \mathrm{~K}$
Errorvar $=0.52, \mathrm{R}^{2}=0.48$

Persamaan struktural di atas menunjukkan bahwa variasi HK, HU, PS, KM, MH, PH dan K menjelaskan $72 \%$ variasi dari IP. Sedangkan IP, KM dan K menjelaskan $48 \%$ variasi dari $\mathrm{P}$.

Besarnya pengaruh dari variabel-variabel eksogen terhadap endogen tertera pada tabel 3 .

Dari Tabel 3, dapat terlihat bahwa faktor determinan terbesar untuk intensi penggunaan aplikasi Go-Pay adalah Motivasi Hedonik, di mana para responden merasa menggunakan aplikasi Go-Pay itu menarik, menyenangkan dan dapat dinikmati. Faktor determinan lainnya adalah Pengaruh Sosial, Kebiasaan dan Persepsi Harga. 
Tabel 2. Uji Signifikansi Model Struktural

\begin{tabular}{|c|c|c|c|}
\hline Hipotesis & Jalur & Nilai t & Kesimpulan \\
\hline 1 & HK $\Rightarrow$ IP & 0.98 & Tidak signifikan (H1 ditolak) \\
\hline 2 & HU $\Rightarrow$ IP & 0.04 & Tidak signifikan (H2 ditolak) \\
\hline 3 & PS $\Rightarrow$ IP & 5.46 & Signifikan (H3 diterima) \\
\hline 4 & KM $\Rightarrow$ IP & -0.65 & Tidak signifikan (H4 ditolak) \\
\hline 5 & MH $\Rightarrow$ IP & 4.10 & Signifikan (H5 diterima) \\
\hline 6 & PH $\Rightarrow$ IP & 2.23 & Signifikan (H6 diterima) \\
\hline 7 & K $\Rightarrow$ IP & 2.49 & Signifikan (H7 diterima) \\
\hline 8 & KM $\Rightarrow$ P & -1.39 & Tidak signifikan (H8 ditolak) \\
\hline 9 & K $\Rightarrow$ P & 8.63 & Signifikan (H9 diterima) \\
\hline 10 & IP $\Rightarrow$ P & 6.00 & Signifikan (H10 diterima) \\
\hline
\end{tabular}

Sumber: Data diolah (2019)

Tabel 3. Besar Pengaruh Variabel Laten

\begin{tabular}{|c|c|c|}
\hline $\begin{array}{l}\text { Variabel yang } \\
\text { Berpengaruh }\end{array}$ & $\begin{array}{l}\text { Variabel yang } \\
\text { Dipengaruhi }\end{array}$ & $\begin{array}{l}\text { Loading } \\
\text { Faktor }\end{array}$ \\
\hline Pengaruh Sosial & Intensi Penggunaan & 0.29 \\
\hline Motivasi Hedonik & Intensi Pengguna & 0.42 \\
\hline Persepsi Harga & Intensi Penggunaan & 0.12 \\
\hline Kebiasaan & Intensi Penggunaan & 0.16 \\
\hline Kebiasaan & Penggunaan & 0.45 \\
\hline Intensi Penggunaan & Penggunaan & 0.40 \\
\hline
\end{tabular}

Sedangkan faktor determinan terbesar yang mempengaruhi Penggunaan adalah faktor Kebiasaan, dan diikuti dengan Intensi Penggunaan. Kondisi yang Mendukung sendiri tidak memberikan pengaruh signifikan terhadap Intensi Penggunaan maupun Penggunaan yang sesungguhnya.

\section{DISKUSI}

Dari hasil penelitian yang diperoleh, maka untuk meningkatkan keinginan penggunaan e-money maupun penggunaan yang sesungguhnya, pengusaha dapat menambahkan fitur-fitur atau insentif yang membuat pengguna merasa senang dan menikmati penggunaan aplikasi. Selain itu dapat pula diadakan promo atau insentif untuk saling berbagi dan meningkatkan pengaruh sosial, serta melakukan kampanye pemasaran untuk membiasakan pengguna menggunakan e-money.

Faktor Harapan Kinerja, Harapan Usaha dan Kondisi Mendukung yang tidak memberikan pengaruh terhadap Intensi Penggunaan maupun penggunaan sesungguhnya menunjukkan bahwa pengguna sudah menganggap manfaat, kemudahan penggunaan aplikasi sebagai hal yang dimiliki oleh aplikasi pada umumnya sehingga tidak lagi menentukan intensi penggunaan aplikasi Go-Pay. Demikian juga kondisi yang mendukung, sudah dipandang sebagai hal yang umum dimiliki pengguna sehingga tidak menentukan intensi pengunaan maupun penggunaan real.

\section{SIMPULAN}

Faktor determinan yang terbesar dari intensi penggunaan aplikasi e-money Go-Pay adalah motivasi hedonik, dan diikuti oleh faktor pengaruh sosial, kebiasaan dan persepsi harga. Maka untuk meningkatkan keinginan untuk menggunakan emoney, pengusaha e-money dapat menambahkan fiturfitur yang membuat pengguna merasa senang dan menikmati penggunaan aplikasi serta memberikan insentif untuk saling berbagi.

Sedangkan variabel penggunaan dipengaruhi secara signifikan positif oleh kebiasaan dan intensi penggunaan, sehingga usaha-usaha untuk meningkatkan intensi penggunaan, ditambah dengan kampanye pemasaran untuk membiasakan penggunaan e-money akan memberikan dampak signifikan terhadap penggunaan e-money.

\section{PENELITIAN LANJUTAN}

Penggunaan convenience sampling dalam penelitian ini dapat membatasi untuk generalisasi hasil temuan, karena itu untuk penelitian selanjutnya dapat dikembangkan dengan menggunakan metode lain misalnya stratified random sampling. Selain itu dapat pula mengembangkan penelitian ini dengan studi mengenai faktor-faktor determinan untuk Motivasi Hedonik penggunaan aplikasi e-money, atau melakukan studi kasus dengan aplikasi e-money yang lain.

\section{UCAPAN TERIMA KASIH}

Penelitian Faktor-Faktor yang Mempengaruhi Adopsi Aplikasi Go-Pay Menggunakan UTAUT2 ini terlaksana berkat hibah dana penelitian dosen tahun akademik 2018-2019 dari Direktorat Pengembangan dan Pengabdian Kepada Masyarakat (P3M) Universitas Bunda Mulia, Jakarta.

\section{DAFTAR PUSTAKA}

[1] Admin, "Electronic money", European Central Bank, [Online]. Tersedia: https://www.ecb.europa.eu/stats/money_credit_banking/electr elec_money/html/index.en.html [Diakses: 18 September 2018].

[2] A.H. Pratama, "[Flash] GO-PAY kini kuasai 30 persen transaksi non tunai di Indonesia", TechinAsia, 21 Desember 2017, [Online]. Tersedia: https://id.techinasia.com/angkaperkembangan-go-pay-2017 [Diakses: 18 September 2018].

[3] Deny, "Faktor-Faktor yang mempengaruhi penggunaan aplikasi BBM oleh toko online UMKM menggunakan revisi model TAM," Jurnal Riset Manajemen dan Bisnis, vol. 1, no.2, hal 93-104, 2016.

[4] Deny dan J.F. Andry, "Faktor penentu penggunaan Facebook oleh toko online menggunakan model TAM," Prosiding SNTI 2017 (hal. 64-71), Jakarta: Fakultas Teknologi Informasi Universitas Tarumanagara Jakarta, 2017. 
[5] F. Deningtyas, "Analisis faktor-faktor yang mempengaruhi penggunaan Go-Pay oleh pengguna layanan Go-Jek di Kota Bandung dengan menggunakan model modifikasi UTAUT2," Bandung: Universitas Telkom, 2017.

[6] F.F. Fadlillah, "Sudah saatnya beralih ke e-money, alat pembayaran zaman now", Kementrian Keuangan Republik Indonesia, 29 Maret 2018, [Online]. Tersedia: https://www.kemenkeu.go.id/publikasi/artikel-danopini/sudah-saatnya-beralih-ke-e-money-alat-pembayaranzaman-now/ [Diakses: 18 September 2018]

[7] J. Hair, W. Black, B. Babin, dan R. Anderson, Multivariate Data Analysis, Englewood Cliffs: Prentice Hall, 2010.

[8] P. Isaias, F. Reis, C. Coutinho, dan J.A. Lencastre, "Empathic technologies for distance/mobile learning: An empirical research based on the unified theory of acceptance and use of technology (UTAUT)," Interactive Technology and Smart Education, vol. 14, no.2, hal. 159-180, 2017.

[9] P. Tak dan S. Panwar, "Using UTAUT 2 model to predict mobile app based shopping: evidences from India," Journal of Indian Business Research," vol. 9, no.3, hal. 248-264, 2017.

[10] R. Rauniar, R. Greg, Y. Jei, dan J. Ben, "Technology acceptance model (TAM) and social media usage: an empirical study on Facebook," Journal of Enterprise Information Management, vol. 27 no.1, hal. 6-30, 2014.

[11] S.R. Setiawan, "Ada Go-Pay, Ovo, T-Cash dan sebagainya, mungkinkah disatukan?", Kompas.com, 15 Februari 2018 [Online].

https://ekonomi.kompas.com/read/2018/02/15/130231826/ada -go-pay-ovo-t-cash-dan-sebagainya-mungkinkah-disatukan [Diakses: 18 September 2018].
[12] S. Widianto, "Pengguna kartu kredit di Indonesia masih minim", Pikiran Rakyat, 7 Februari 2017, [Online]. Tersedia: http://www.pikiranrakyat.com/ekonomi/2017/02/07/pengguna -kartu-kredit-di-indonesia-masih-minim-392777 [Diakses 18 September 2018].

[13] U. Sekaran dan R. Bougie, Research Methods for Business, 5th Edition, London: Wiley, 2014

[14] V. Venkatesh, J.Y. Thong, dan X. Xu, "Consumer acceptance and use of information technology: Extending The Unified Theory of Acceptance and Use of Technology," MIS Quarterly, vol. 36, no. 1, hal. 157-178, 2012.

[15] V. Venkatesh, J.Y. Thong, dan X. Xu, "Unified theory of acceptance and use of technology: A synthesis and the road ahead," Journal of the Association for Information System, vol. 17, no. 5, hal. 328-376, 2016.

[16] W.K. Pertiwi, "Saingi Go-Pay, Ovo bakal bisa dipakai transaksi di warung", Kompas.com, 2 Juli 2018, [Online]. Tersedia:

https://tekno.kompas.com/read/2018/07/02/08040087/saingigo-pay-ovo-bakal-bisa-dipakai-transaksi-di-warung [Diakses: 18 September 2018] 